$\operatorname{cocos}(1996), 11,69-78$

Printed in Sri Lanka

\title{
IMPROVEMENT OF SEEDLING QUALITY IN POLYBAGS THROUGH MANIPULATION OF POTTING MEDIA
}

\author{
L Perera, R R A Peries and R Jayatileke \\ Coconut Research Institute, Lunuwila, Sri Lanka
}

\begin{abstract}
Potting mixtures containing different proportions of river sand were used for raising coconut seedlings in polybags with and without fertilizer, to evaluate their growth and vigour after seed nuts were allowed to germinate on a pre - nursery bed and then transplanted. The substitution of topsoil in the polybag mixtures with river sand had no significant effect on the development of coconut seedlings. It was found that pure river sand alone could be successfully used, provided seedlings were kept free from water deficit and in this respect the first seven months from seed nut laying was found to be critical.
\end{abstract}

Application of fertilizer improved the seedling height and girth but this effect was significant only five months after seed nut laying. However, in this study the improvement in seedling vigour was inadequate to justify the extra input on fertilizer.

\section{INTRODUCTION}

Raising coconut seedlings in polybags (Wuidart, 1981) is now very popular in most coconut growing countries and their advantages and disadvantages in replanting programmes have been well documented (Harries, 1983; Maravilla, 1986; Peries and Everand, 1994).

In a recent study carried out in Sri Lanka (Peries and Everard, 1991), it was shown that river sand could be a successful alternative to the more expensive potting media currently used in polybags (Ho et al., 1978; Cano et al., 1989). However, the poor growth of seedling in their experiment was mainly due to the slow germination rate in river sand. The authors have suggested a practical alternative; to lay the seed nuts in a pre-nursery bed to overcome the germination problem, and the application of nutrients to rectify the poor growth rate in river sand. Despite the fact that seed nuts contain adequate nutrients for germination and growth (Child, 1974), under certain circumstances it has been shown that growth and vigour of seedlings can be improved through the addition of fertilizer (Mathew and Ramadasan, 1964; Maravilla, 1986). 
The current study was designed to test the hypothesis that seed nuts raised in a pre-nursery and subsequently grown in a river sand potting media would respond better to fertilizer application. A secondary objective was also to develop and recommend a suitable package to improve the nutritionally poor media.

\section{MATERIALS AND METHODS}

The study was conducted at the.Bandirippuwa estate research nursery, beginning in May 1991. The seed nuts T X T (CRIC 60) from the Isolated Seed Garden (ISG) at Ambakelle were used and were obtained from the 3rd pick during May 1991. One thousand seed nuts (three times the requirement) were laid in a conventional prenursery bed (Peries, 1984) for subsequent transplanting in polybags.

The seed bed took the dimensions of a conventional pre-nursery i.e., $150 \mathrm{~cm}$ wide, with unspecified length, with the earth raised to about $15 \mathrm{~cm}$. The nuts were laid verticaly at close spacing, leaving about $5 \mathrm{~cm}$ from one another on each side $\left(16 \mathrm{Nut} / \mathrm{m}^{2}\right)$.

The beds were irrigated once in three days, beginning from the seventh day after there was no rain for a continuous spell of seven days or more. No fertilizer was applied on the beds. Dry coconut fronds were used as a mulch to conserve the soil water.

All sprouted seed nuts with sprout heights ranging from 9 to $19 \mathrm{~cm}$ were picked out and transplanted vertically in polybags at 18 weeks after laying in the prenursery. The bags of $40 \mathrm{~cm} \times 28 \mathrm{~cm}$ with gussets $(15 \mathrm{~cm})$ made up of 800 gauge polyethylene were filled up to $2 / 3$ rd with the different potting mixtures. The lower half of each bag was pierced to have 12 holes in a row to allow excess water to drain off. The different potting mixtures and fertilizer treatments are summarized in Table 1.

The current fertilizer recommendation is to apply $70 \mathrm{~g}$ of a mixture containing 3 parts of Ammonium Sulphate, 1 part of Concentrated Super Phosphate, 2 parts of Muriate of Potash and 1 part of Keserite per seedling at 24 weeks after seed nut laying (Peries, 1984). Half the quantity of polybags (25 bags) prepared with each potting mixture were supplied with the above mixture in four equal split applications, the first at transplanting and then at 24,28 , and 30 weeks after seed nut laying. The other 25 polybags did not receive any fertilizer.

The seedlings were spaced at $60 \times 60 \times 60 \mathrm{~cm}$ triangular in a completely randomized design (CRD). The seedlings were kept free from water deficit throughout the experimènt by irrigating whenever there was no rain.

Seedling height, girth at collar and number of fully opened leaves were recorded 


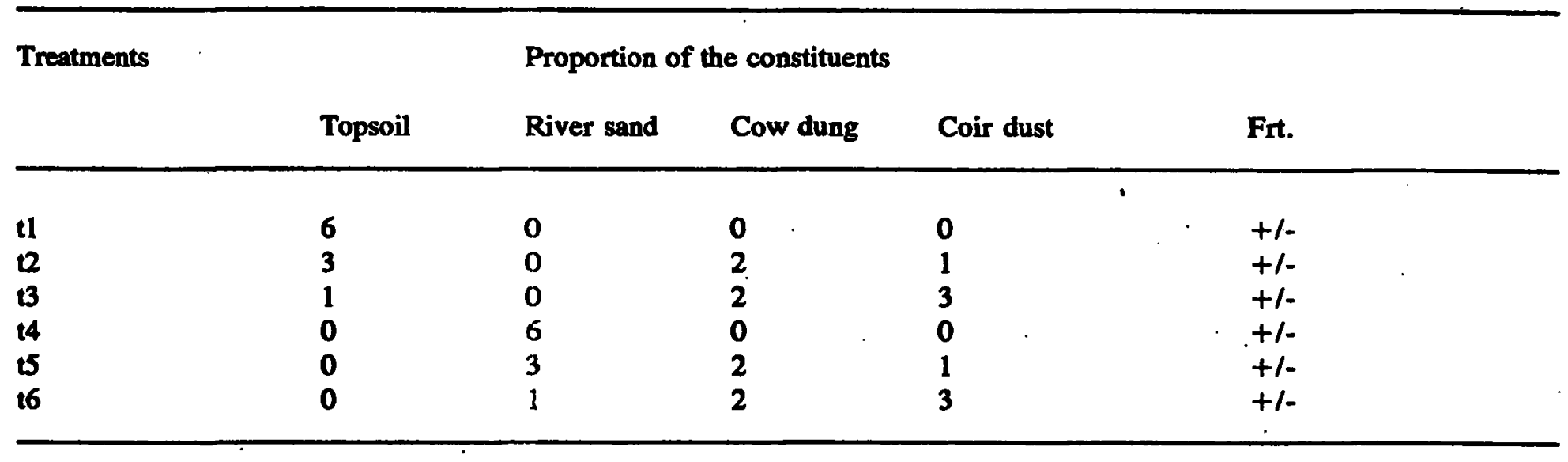


at transplanting (4 months after seed nut laying) and then at 5, 6, 7, 8, 9 and 10 months after laying in the pre-nursery.

The data were analyzed using the analysis of variance procedure to compare the treatment differences in the parameters recorded with adjustment through covariance analysis. Initial seedling height, girth at collar and number of leaves were used as the covariate for each analysis, respectively.

\section{RESULTS AND DISCUSSION}

There was no interaction between potting media and fertilizer level indicating that potting media and fertilizer levels were independent. The temporal change in seedling height from 5 to 10 months after seed nut laying in the pre-nursery is shown in Figure 1. The treatment with one part of topsoil, two parts of cow dung and three parts of coir dust (T3) led to a significant increase in seedling height (79.9 cm) compared to T1, T2, T4 and T6 at 10 months $(74.4 \mathrm{~cm}, 73.5 \mathrm{~cm}, 71 \mathrm{~cm}$, $72.5 \mathrm{~cm}$ respectively). The treatments $\mathrm{T3}$ and $\mathrm{TS}$ (Three parts of river sand, two parts of cow dung and one part of coir dust) were not significantly different from each other $(75.6 \mathrm{~cm})$. Eventhough a similar trend was visible from 5 months onwards, the difference was not significant until 10 months.

Figure 2 shows the temporal increase in girth at collar of seedlings during the same period. The girth was highest in $T 3(8.8 \mathrm{~cm})$, though it was not significantly different from T5 $(8.7 \mathrm{~cm})$ and T6 $(8.6 \mathrm{~cm})$ at 8 months and this difference was maintained up to 10 months.

The mean number of fully opened leaves at $5,6,7,8,9$ and 10 months is shown in Figure 3. The treatment difference began to show up only after 8 months. The treatment T3 again produced the highest leaf number (5.1) followed by T5 and T6 (both 4.8 ) at 9 months. The difference between T3 and T5 continued up to 10 months $(6.1$ vs 5.8$)$. These differences were, however, not significant.

The results indicated that the substitution of topsoil in the polybag potting mixture with river sand had little effect on the growth and development of coconut seedlings, when seed nuts were transplanted from a pre-nursery bed. Moveover, even with river sand alone, differences were observed only after 7 months from seed nut laying at which age the seedlings could be transplanted in the field. Peries and Everard (1991) reported that the seedling vigour in terms of height, girth and number of fully opened leaves, was reduced in sand-substituted media at 30 weeks (i.e., after 7 months) with direct sowing in polybags. This reduction in seedling vigour was associated with a slower rate of germination in the sand containing media but in their case seadlings of different physiological ages were compared. However the situation was different when seed nuts were selected from a pre-nursery bed immediately after sprouting and transplanted in the polybag. 


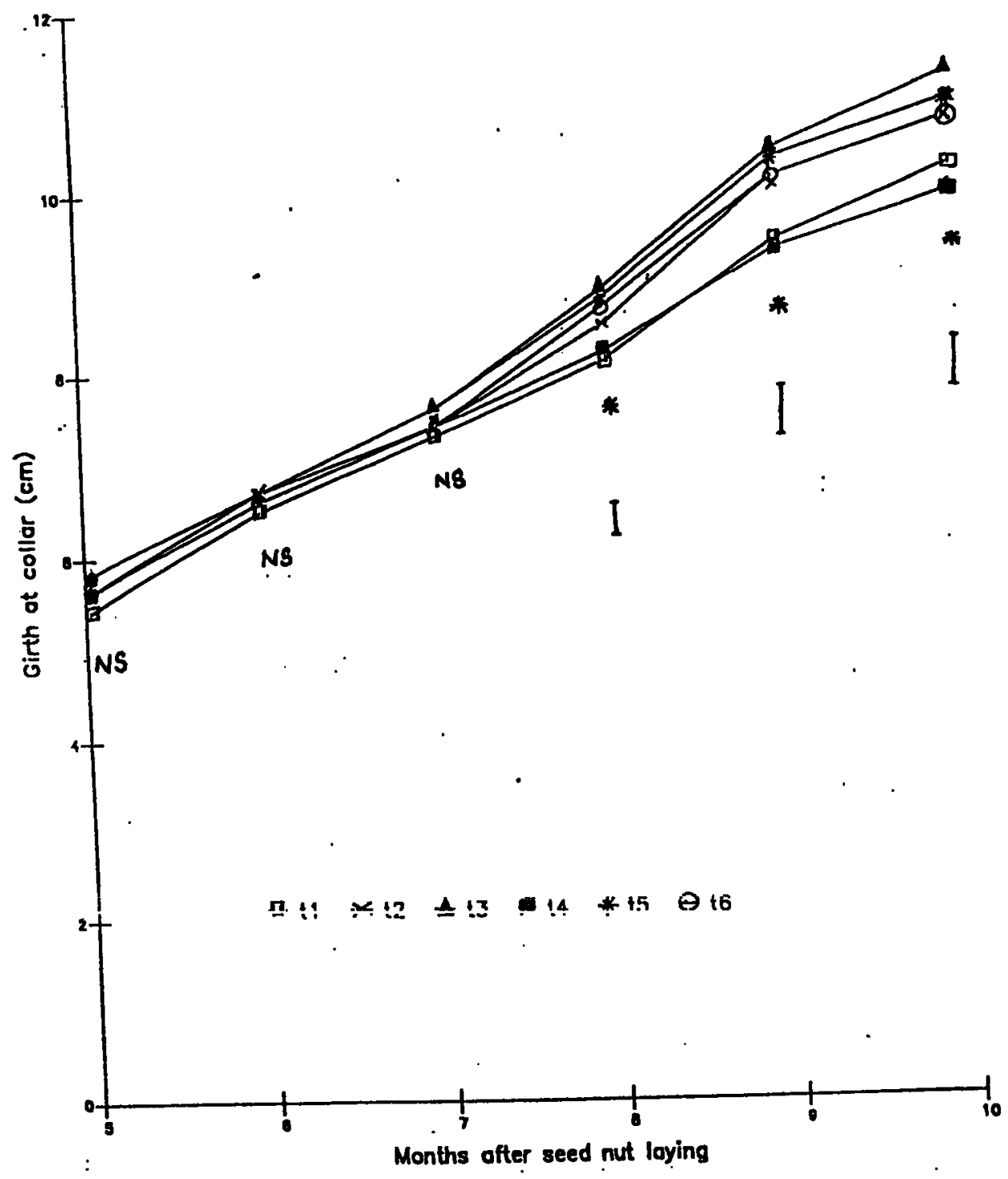

Figure 1 The temporal increase in seedling height in the different treatments. Vertical bar indicate the LSD $(p<0.05)$ 



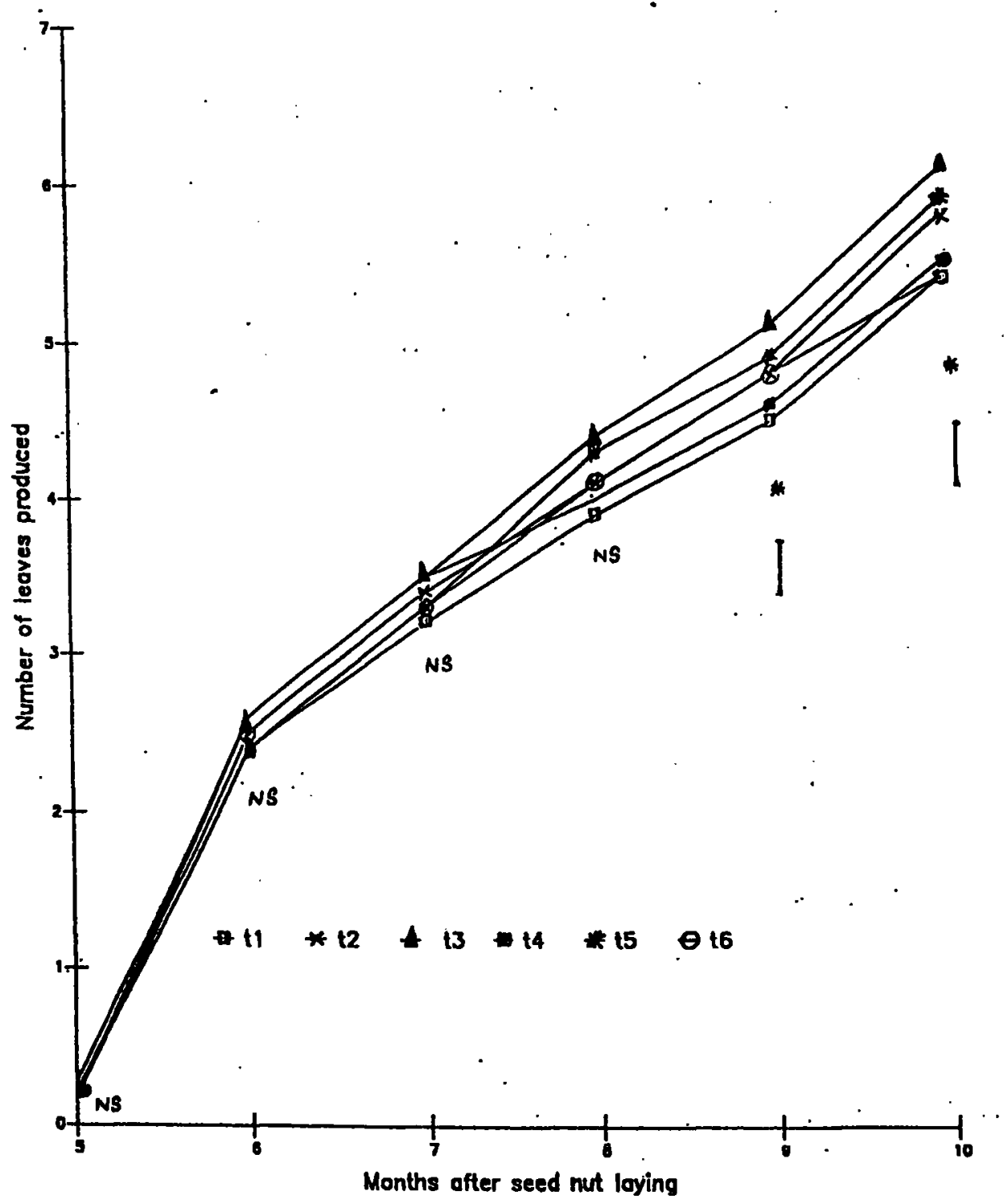

Figure 3 The temporal increase in number of leaves in the different treatments. Vertical bars indicate the LSD $(p<0.05)$

75 
Table 2. The temporal change in seedling height, girth at collar and total number of leaves at monthly intervals after seed nut laying in response to fertilizer application

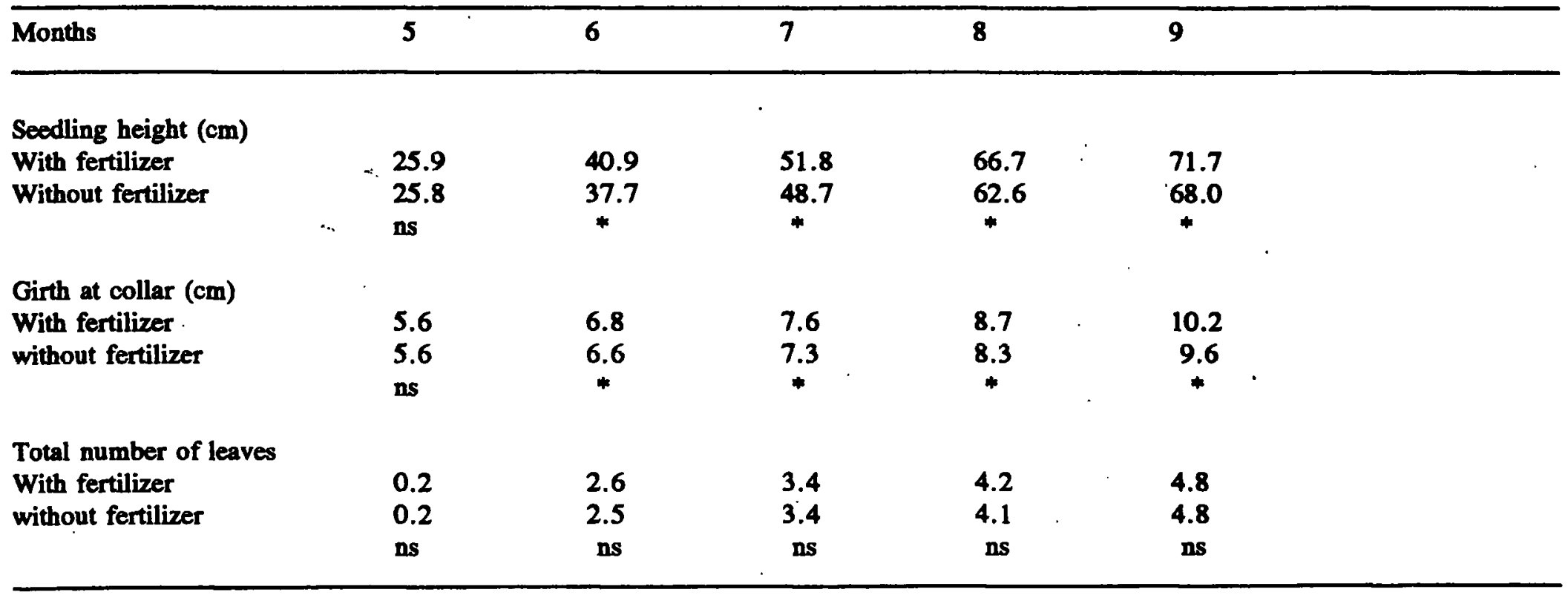

ns - non significance $(P<0.05)$

* - significance $\quad(P<0.05)$ 
Application of fertilizer on the other hand, had a significant effect on seedling vigour (Table 2) by improving the height and girth only after 5 months from seed laying. Although it had no effect on the number of fully opened leaves, it is likely to have an impact on leaf area (data were not recorded). Almaden and Santiago (1980) have also reported similar results with different levels of Nitrogen and Potassium. However, in the current study the improvement in seedling vigour was inadequate to justify the extra input of fertilizer.

\section{CONCLUSIONS}

The results of this study indicated that when seed nuts were transplanted from a pre-nursery and raised in polybags, fertilizer application would only be necessary under conditions of extended nursery period. River sand could be successfully used as an alternative to topsoil in polybag potting mixtures. The mixture containing 3 parts of river sand, 2 parts of cow dung and 1 part of coir dust (TS) (i.e. 3:2:1) was shown to be the best while the 1:2:3 mixture also gave a similar result. Therefore if topsoil was available in limited quantity, 1 part topsoil, 2 parts cow dung and 3 parts coir dust (T3) may also be used as an alternative.

\section{ACKNOWLEDGEMENTS}

We wish to thank Mr. J.M.D.T. Everard and Dr. (Mrs.) W.M.U. Fernando, our colleagues in the Genetics and Plant Breeding Division and Mr. D.T. Mathes, Head, Biometry division for their valuable suggestions on the manuscript.

\section{REFERENCES}

Almaden, E.A. and Santiago, R.M. (1980). Response of coconut seedlings to spacing and application of Nitrogen and Potassium. Ann. Trop. Res. 289 - 95.

Cano, S. B., Santos, G. A. and Bahala, R. T. (1989). Germination, growth and development of coconut seedlings in relation to seed nut preparation, position and polybagging. Cited in Training manual of short course on collection, conservation and characterization of coconut genetic resources, Philippine, 1990.

Child, R. (1974). Nutritional requirements and fertilizer practice in coconuts. Coconut. $130-156$ pp, 2nd ed, Longman, London.

Harries, H.C. (1983). A ten point coconut nursery programme to avoid germination problems. Planter, Kuala Lumpur, 59, 207- 214.

Ho, D.T., Loh, H.P. and Chan, E. (1978). Germination, nursery practices and field planting techniques for the MAWA hybrid coconut. Proceedings of the International Conference on Cocoa and Coconut, 1978. 
Maravilla, J.N. (1986). Nutrition and fertilizer of coconut seedlings in polybags. Philippine J. Coconut Stud. Vol ii (i) 44 - 56.

Mathew, C. and Ramadasen, A (1964).Effect of N, P, K and nutrients on the growth of the coconut seedlings. Indian Coconut Journal. 17(4) 114 - 117.

Peries, R.R.A. (1984). Some observations on the pre - nursery system for raising coconut seedlings. Cocos 2: $10-17$.

Peries, R.R.A. and Everard J.M.D.T. (1991-1993). River sand as an alternative to topsoil for raising coconut seedling in polybags. Cocos 9: $40-46$.

Wuidart, W (1981).Production of coconut planting material - The polybag nursery Oleagineux, 36: 367 - 373. 